\title{
ОБРОБКА СИГНАЛІВ ТА МАТЕМАТИЧНЕ МОДЕЛЮВАННЯ ДИНАМІЧНИХ ОБ'ЄКТІВ ЗА ДОПОМОГОЮ ЇХ ПРЕДСТАВЛЕННЯ ЯК ДИСКРЕТНИХ ДЖЕРЕЛ ІНФОРМАЦІЇ
}

\author{
О.В. Муль, А.І. Сегін
}

Резюме: Моделювання процесів в динамічних системах різної фізичної природи $\epsilon$ важливою проблемою, яка може бути успішно вирішеною за допомогою їх представлення як дискретних джерел інформачії та злиття сигналів різних сенсорів в систему візуального контролю характеристик об'єкта. Зробленои спробу об'єднати математичний апарат для опису динамічних об'єктів на основі системи диференщійних рівнянь з їх описом за допомогою статистичних, кореляційних, ентропійних, логічно-статистичних моделей, що дозволить провести паралелізацію обчислювальних процеедр та підвищити точність моделей.

Ключові слова: - обробка сигналів, джерела дискретної інформачії.

\section{1. ОПИС ДИСКРЕТНИХ ДЖЕРЕЛ ІНФОРМАЦІЇ ЗА ДОПОМОГОЮ СИСТЕМ ДИФЕРЕНЦІАЛЬНИХ РІВНЯНЬ}

Моделювання процесів в динамічних системах різної фізичної природи є актуальною проблемою, яка успішно вирішується шляхом їх представлення в якості дискретних джерел інформації (ДДІ) і злиття сигналів різних сенсорів, які представляють системні характеристики об' єктів.

Для моделювання інформаційних систем, сигнали яких відомі в будь-який момент часу, як правило, використовується математичний апарат, який дозволяє знаходити частоти детермінованих сигналів. У випадку систем 3 ДДІ відповідними математичними моделями $\epsilon$ системи звичайних диференціальних рівнянь.

Так, для аналізу динаміки складних технічних систем можна використовувати нелінійні математичні моделі у вигляді системи диференціальних рівнянь п’ятого порядку [1]:

$$
\mathrm{T}_{\mathrm{e}} \dot{\mathrm{M}}+\mathrm{M}=\beta\left(\omega_{\mathrm{o}}-\dot{\varphi}_{1}\right) \text {, }
$$

$\mathrm{J}_{1} \ddot{\varphi}_{1}+\mathrm{b}_{12}\left(\dot{\varphi}_{1}-\dot{\varphi}_{2}\right)+\mathrm{c}_{12}\left(\varphi_{1}-\varphi_{2}\right)=\mathrm{M},(1)$

$J_{2} \ddot{\varphi}_{2}-b_{12}\left(\dot{\varphi}_{1}-\dot{\varphi}_{2}\right)-c_{12}\left(\varphi_{1}-\varphi_{2}\right)=$.

$-m_{o}\left(\alpha_{o}-\alpha_{1} \dot{\varphi}_{2}+\alpha_{3} \dot{\varphi}_{2}^{3}\right)$

Таке представлення дозволяє проводити дослідження можливих динамічних процесів, включаючи багаточастотні коливальні процеси, які можуть мати місце в розглянутому класі систем, за допомогою їхнього опису в базисі Фур'є.

\section{2. АМПЛІТУДНІ МОДЕЛІ СИГНАЛІВ}

Крім математичного моделювання динамічних об'єктів на основі звичайних диференціальних рівнянь широке застосування та перспективу мають наступні класи моделей: статистичні, кореляційні, спектральні, ентропійні, логіко-статистичні та Хемінгові [2].

Основою для побудови будь-якої сигнальної моделі є модель, що відображає значення амплітуди досліджуваного процесу (рис. 1). Процес може бути або неперервним або носити дискретний характер. Таким чином, інформаційні моделі теж можна поділити на дві групи: аналогові і дискретні. Слід зауважити, що подання значень процесу в дискретному вигляді більш зручне для подальшого аналізу, оскільки сучасна обчислювальна техніка переважно використовує дискретні базиси. Очевидно, що властивості аналогових джерел інформації можуть бути описані за допомогою дискретних із заданою точністю.

Як відомо, існує три способи переходу від аналогової величини $x(t)$ до дискретної $x_{i}$ :

$$
x_{i}=\hat{E}\left[\frac{x(t)}{\Delta}\right] ; \quad x_{i}=\stackrel{\vee}{E}\left[\frac{x(t)}{\Delta}\right] ; \quad x_{i}=\widetilde{E}\left[\frac{x(t)}{\Delta}\right],
$$

де $\stackrel{\wedge}{E}, \stackrel{\vee}{E}, \widetilde{E}$-цілочисельні функції з округленням відповідно до більшого, меншого і найближчого цілого; $\Delta-$ крок квантування [3].

Крок квантування $\Delta$ вибирається у відповідності до заданої точності. Згідно цього кроку та динаміки процесу, найчастіше на основі 


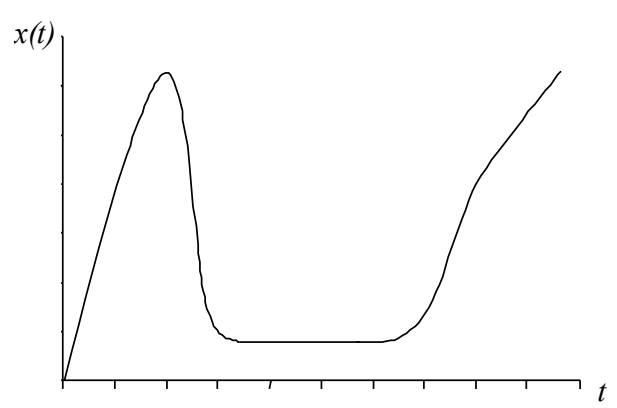

a)

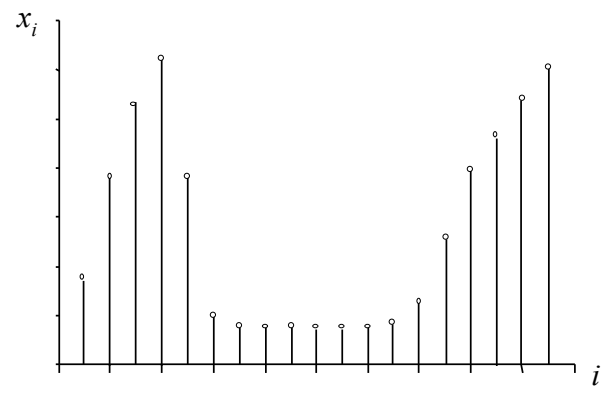

б)

Рис. 1. Лінійні моделі: а) аналогових сигналів; б) дискретних сигналів.

динаміки автокореляційних функцій [3], визначається час дискретизації $\Delta t$. Ідеальна дискретизація аналогового сигналу $x(t) 3$ частотою $f_{d}$ здійснюється шляхом множення сигналу $x(t)$ на суму імпульсів Дірака 3 періодичністю $t_{d}=\frac{1}{f_{d}}$ :

$$
D=\sum_{i=-\infty}^{\infty} \delta\left(t-\frac{i}{f_{d}}\right) .
$$

Позначивши дискретизований сигнал $x_{i}$, отримаємо наступний вираз:

$$
\begin{aligned}
& x_{i}=\sum_{k=-\infty}^{\infty} x\left(\frac{i}{f_{d}}\right) \cdot \delta\left(t-\frac{i}{f_{d}}\right) \quad \text { або } \\
& x_{i}=x(t) \cdot \sum_{k=-\infty}^{\infty} \delta\left(t-\frac{i}{f_{d}}\right) .
\end{aligned}
$$

\section{3. СТАТИСТ ИЧНІ ТА КОРЕЛЯЦІЙНІ МОДЕЛІ}

Одними з найпростіших в побудові та реалізації є статистичні та кореляційні моделі [4]. Високий рівень розвитку і широке впровадження мікропроцесорної техніки, великихінтегральних схем, спецпроцесорів для обробки повідомлень забезпечує простоту реалізації та можливість широкого використання моделей цієї групи.

До класу статистичних моделей належать різні модифікації математичного сподівання:

вибіркове математичне сподівання $M_{x}=\frac{1}{n} \sum_{i=1}^{n} x_{i}$,

ковзне математичне сподівання $M_{j}=\frac{1}{n} \sum_{i=1}^{n} x_{i+j}$

та зважене математичне сподівання $M_{p}=\sum_{i=1}^{n} p_{i} x_{i}$; а також дисперсія $D_{x}=\frac{1}{n} \sum_{i=1}^{n}\left(x_{i}-M_{x}\right)^{2}=\frac{1}{n} \sum_{i=1}^{n} \hat{x}_{i}^{2}$

та середньоквадратичне відхилення $\sigma_{x}=\sqrt{D_{x}}$, де $j$ - дискретний зсув в часі; $p_{i}-$ значення вагової функції в дискретному просторі, причому $\sum_{i=1}^{n} p_{i}=1$.

Кореляційні моделі базуються на відомих кореляційних функціях:

кореляції $R_{x x}(j)=\frac{1}{n} \sum_{i=1}^{n} \stackrel{\wp}{x}_{i} \cdot \stackrel{\circ}{x}_{i+j}$;

коваріації $K_{x x}(j)=\frac{1}{n} \sum_{i=1}^{n} x_{i} \cdot x_{i+j}$;

нормованої кореляції $\rho_{x x}(j)=\frac{R_{x x}(j)}{D_{x}}$;

знаковій $H_{x x}(j)=\frac{1}{n} \sum_{i=1}^{n} \operatorname{sgn}\left[\mathfrak{x}_{i}\right] \cdot \operatorname{sgn}\left[\mathfrak{x}_{i+j}\right]$;

полярній $P_{x x}(j)=\frac{1}{n} \sum_{i=1}^{n} \hat{x}_{i} \cdot \operatorname{sgn}\left[\mathfrak{x}_{i+j}\right]$

або $P_{x x}(j)=\frac{1}{n} \sum_{i=1}^{n} x_{i} \cdot \operatorname{sgn}\left[\stackrel{\circ}{x}_{i+j}\right]$;

структурній $C_{x x}(j)=\frac{1}{n} \sum_{i=1}^{n}\left(x_{i}-x_{i+j}\right)^{2}$;

модульній $G_{x x}(j)=\frac{1}{n} \sum_{i=1}^{n}\left|x_{i}-x_{i+j}\right|$;

еквівалентності $\stackrel{\vee}{F} x x(j)=\frac{1}{n} \sum_{i=1}^{n} z_{i}\left[x_{i}, x_{i+j}\right]$ або 


$$
\begin{aligned}
& \hat{F}_{x x}(j)=\frac{1}{n} \sum_{i=1}^{n} \hat{z}_{i}\left[x_{i}, x_{i+j}\right], \\
& \text { де } \begin{array}{l}
\operatorname{sgn}\left[x_{i}\right]=\left\{\begin{array}{l}
1, x_{i}>0 ; \\
0, x_{i}=0 \\
1, x_{i}<0
\end{array}-\right.\text { знакова функція; }
\end{array} \\
& \check{v}_{i}\left[x_{i}, x_{i+j}\right]=\stackrel{\vee}{z}_{i}=\left\{\begin{array}{l}
x_{i}, \text { nри } x_{i} \leq x_{i+j}, \\
x_{i+j}, \text { nри } x_{i}>x_{i+j} .
\end{array} .\right. \text { функ- }
\end{aligned}
$$

ція «менше 3 двох»;

$$
\hat{z}_{i}\left[x_{i}, x_{i+j}\right]=\hat{z}_{i}=\left\{\begin{array}{l}
x_{i}, \text { якщо } x_{i} \geq x_{i+j}, \\
x_{i+j}, \text { якщо } x_{i}<x_{i+j},
\end{array},\right. \text { функ- }
$$

ція «більше 3 двох».

Між наведеними оцінками кореляційних функцій можна встановити аналітичні залежності, які для стаціонарних сигналів матимуть Вигляд:

$$
\begin{aligned}
& K_{x x}(j)=R_{x x}(j)+M_{x}^{2} ; \\
& C_{x x}(j)=2\left|D_{x}+M_{x}^{2}-K_{x x}(j)\right|=2\left[D_{x}-R_{x x}(j)\right] ; \\
& G_{x x}(j)=2\left(M_{x}-\stackrel{\vee}{F}_{x x}(j)\right) ; \\
& \hat{F}_{x x}(j)=2 M_{x}-\stackrel{\vee}{F}_{x x}(j),
\end{aligned}
$$

а також статистичні залежності [5]:

$$
\begin{aligned}
& \rho_{x x}(j)=1-\frac{G_{x x}^{2}(j)}{2 \mu_{x} \sigma_{x}^{2}} ; \quad \rho_{x x}(j)=\frac{1}{\mu_{x} \sigma_{x}} P_{x x}(j) ; \\
& \rho_{x x}(j)=\sin \left(\frac{1}{\mu^{2}} H_{x x}(j)\right) ;
\end{aligned}
$$

де $\mu_{x}$ - коефіцієнт, що залежить від закону розподілу.

Для нормального закону розподілу [5-7] $\mu=\sqrt{\frac{2}{\pi}}$, що дозволяє записати:

$$
\begin{aligned}
& G_{x x}(j)=\frac{2}{\sqrt{\pi}} \sqrt{D_{x}-R_{x x}(j)} ; \\
& \rho_{x x}(j)=\sin \left[\frac{\pi}{2} H_{x x}(j)\right] ; \\
& \rho_{x x}(j)=\sqrt{\frac{\pi}{2}} \cdot \frac{P_{x x}(j)}{\sigma_{x}} .
\end{aligned}
$$

Особливими кореляційними оцінками є наступні:

$$
\begin{aligned}
& B_{x x}(j)=\frac{1}{n} \sum_{i=1}^{n} x_{i}+x_{i+j} \quad \text { та } \\
& Q_{x x}(j)=\frac{1}{n} \sum_{i=1}^{n} x_{i}^{2}+x_{i+j}^{2},
\end{aligned}
$$

які вироджуються в статистичні характеристики стаціонарних сигналів $B_{x x}(j)=2 M_{x}$ i $Q_{x x}(j)=2\left(D_{x}+M_{x}^{2}\right)$ та втрачають властивість відображати кореляційні зв'язки. Ефект виродження виникає через те, що оцінки (3) є сумою симетричних функцій:

$$
\begin{gathered}
B_{x x}(j)=2 \stackrel{\vee}{F}_{x x}^{2}(j)+G_{x x}(j), \\
Q_{x x}(j)=2 \stackrel{\vee}{F}_{x x}^{2}(j)+2 \frac{1}{n} \sum_{i}^{n} \stackrel{\vee}{z}_{i} \cdot\left|x_{i}-x_{i+j}\right|+C_{x x}(j),
\end{gathered}
$$

$$
\text { де } \stackrel{\vee}{F}_{x x}^{2}(j)=\frac{1}{n} \sum_{i=1}^{n} \stackrel{\vee}{z}_{i}^{2}\left(x_{i}, x_{i+j}\right) \text { - квадратична }
$$
функція еквівалентності.

$2^{3}$ другого виразу (4) видно, що між функціями $\stackrel{\vee}{F}_{x x}^{2}(j)$ i $C_{x x}(j)$ існує аналітичний зв'язок, який виражається через функцію

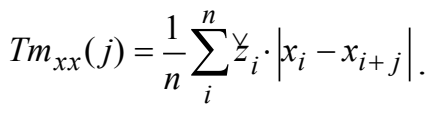

По аналогії введемо інші функції, які по відношенню до $\operatorname{Tm}_{x x}(j)$ не несуть нової інформації, але можуть бути більш зручними в плані обчислення:

$$
\begin{gathered}
T b_{x x}(j)=\frac{1}{n} \sum_{i}^{n} \hat{z}_{i} \cdot\left|x_{i}-x_{i+j}\right| \\
T 1_{\mathrm{xx}}(\mathrm{j})=\frac{1}{\mathrm{n}} \sum_{\mathrm{i}}^{\mathrm{n}} \mathrm{x}_{\mathrm{i}} \cdot\left|\mathrm{x}_{\mathrm{i}}-\mathrm{x}_{\mathrm{i}+\mathrm{j}}\right|=\mathrm{T} 2_{\mathrm{xx}}(\mathrm{j})=\frac{1}{\mathrm{n}} \sum_{\mathrm{i}}^{\mathrm{n}} \mathrm{x}_{\mathrm{i}+\mathrm{j}} \cdot\left|\mathrm{x}_{\mathrm{i}}-\mathrm{x}_{\mathrm{i}+\mathrm{j}}\right| \\
T s_{x x}(j)=\frac{1}{n} \sum_{i}^{n}\left(x_{i}+x_{i+j}\right) \cdot\left|x_{i}-x_{i+j}\right|
\end{gathered}
$$

Здійснивши нескладні перетворення, виразимо функції (6) через функції (5):

$$
\begin{aligned}
& T b_{x x}(j)=T m_{x x}(j)+C_{x x}(j), \\
& T 1_{x x}(j)=T m_{x x}(j)+C_{x x}(j) / 2, \\
& T s_{x x}(j)=2 T m_{x x}(j)+C_{x x}(j) .
\end{aligned}
$$

Тоді на основі залежності (4) можна записати:

$$
\operatorname{Tm}_{x x}(j)=K_{x x}(j)-2 \stackrel{\vee}{F_{x x}^{2}}(j) .
$$



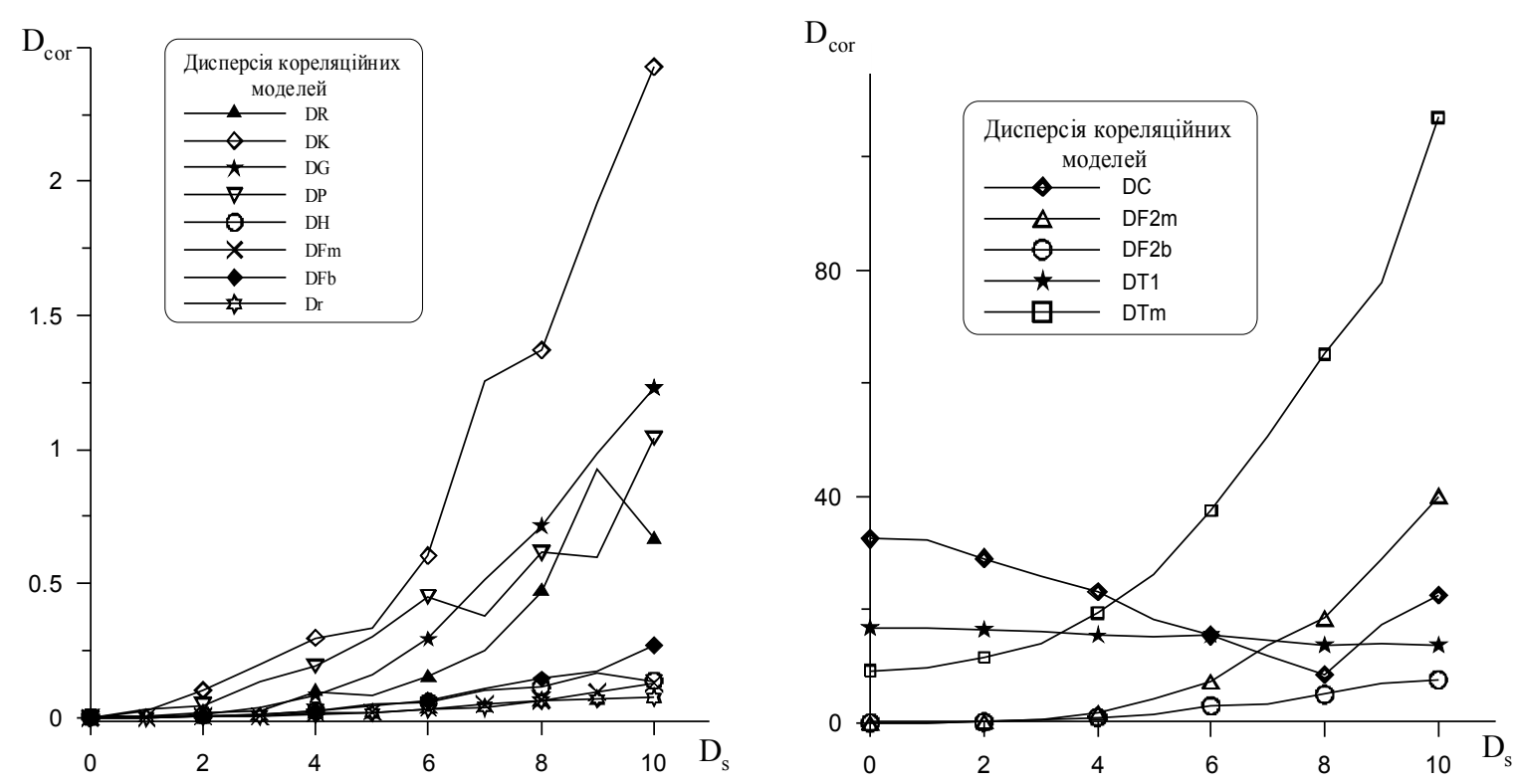

Рис. 2. Графіки зміни дисперсї кореляційних моделей при збільщенні дисперсії шуму з нормальним законом розподілу.

На практиці часто неможливо отримати ідеальні значення сигналів, які не мають спотворень. Більшість сигналів зазнають впливу завад різної природи, які спричиняють шуми, що мають переважно випадковий характер 3 нормальним законом розподілу. Тому доцільним є дослідити вплив таких шумів на адекватність кореляційних моделей. На рис. 2 показана зміна дисперсії кореляційних моделей в залежності від зростання дисперсії шуму з нормальним законом розподілом при математичному сподіванні рівному одиниці. Як видно з графіків, найменш чутливими до шуму є знакова, нормована та еквівалентні кореляційні моделі, а нововведена кореляційна модель характеризується найбільшою чутливістю до збільшення дисперсії шуму.

\section{4. ЕНТРОПІЙНІ МОДЕЛІ СИГНАЛІВ}

Важливим параметром дискретних джерел інформації $є$ ентропія. В роботі Л. Г. Лапи [6] відмічено, що для визначення ймовірнисних показників джерел інформації (ДІ) необхідні детальні характеристики кореляційних зв'язків між різними символами. Там же підкреслюється, що чим більша кореляція між станами ДI, тим більш нерівноймовірний розподіл умовної ймовірності визначення ентропії ДІз залежними станами, що приводить до зменшення ентропії джерела. Л. Г. Лапа також звертає увагу на те, що функція ентропії Хартлі користується виключно одновимірними розподілами, в той час як кореляційна функція використовує двовимірні ймовірнісні розподіли. Тому принципово оцінка ентропії на базі кореляційної функціїзмістовніша, ніж функція ентропії Хартлі.

Складність обчислення багатовимірних розподілів суттєво обмежує можливості використання шеннонівських оцінок ентропії для ДІ 3 незалежними та статистично залежними станами при інженерному розрахунку ї властивостей, особливо якщо дослідження інформаційних параметрів конкретних джерел ведуться комп'ютерною системою в реальному масштабі часу. Тому реалізація безпосереднього зв' язку кореляційної функції з розподілами ймовірностей станів і ентропією ДІ $є$ досить перспективною.

Чисельний розрахунок ентропії дискретного джерела інформації 3 нерівноймовірними корельованими станами здійснюється у відповідності із виразом:

$$
H\left[x_{i}, x_{i+j}\right]=\log _{2} 2 \pi e+\log _{2} \sigma_{\circ}^{2}+\frac{1}{2} \log _{2}\left[1-\rho_{x x}^{2}(j)\right],
$$

де перший елемент є константою інформаційної міри, що пов'язана 3 типом закону розподілу випадкової величини, другий елемент визначає дисперсію випадкових станів ДІ:

$$
\sigma_{\mathrm{o}}^{2}=\frac{1}{N-1} \sum_{i=1}^{N}\left(x_{i}-\frac{1}{N} \sum_{i=1}^{N} x_{i}\right)^{2},
$$

а третій елемент характеризує взаємну 
ентропію корельованих нерівноймовірних станів ДІ за допомогою квадрату нормованої функції автокореляції:

$$
\rho_{x x}(j)=\frac{\frac{1}{N} \sum_{i=1}^{N}\left(x_{i}-\frac{1}{N} \sum_{i=1}^{N} x_{i}\right) \cdot\left(x_{i+j}-\frac{1}{N} \sum_{i=1}^{N} x_{i}\right)}{\frac{1}{N-1} \sum_{i=1}^{N}\left(x_{i}-\frac{1}{N} \sum_{i=1}^{N} x_{i}\right)^{2}} .
$$

Розрахунок ентропії ДІ на основі оцінки нормованої автокореляційної функції $\rho_{x x}(j) \epsilon$ незручним при обчисленні в зв'язку з необхідністю центрування послідовності $x_{i}$.

На основі поданих вище аналітичних взаємозв'язків між кореляційними функціями можна представити ентропійну модель через інші кореляційні функції:

$$
\begin{aligned}
& H\left(x_{i}, x_{i+j}\right)=\log _{2} 2 \pi e+\frac{1}{2} \log _{2}\left(\left[D_{x}-R_{x x}(j)\right] \cdot\left[D_{x}+R_{x x}(j)\right]\right) ; \\
& H\left(x_{i}, x_{i+j}\right)=\log _{2} 2 \pi e+\frac{1}{2} \log _{2}\left(\left[D_{x}-K_{x x}(j)\right] \cdot\left[D_{x}+K_{x x}(j)\right]\right) .
\end{aligned}
$$

Якщо оцінити середнє, отримаємо робочі формули міри ентропії через структурну, модульну та еквівалентну кореляційні моделі:

$$
\begin{gathered}
\overline{H\left(x_{i}, x_{i+j}\right)}=\frac{1}{T} \sum_{j=1}^{T} \log _{2}(2 \pi e)^{2}\left[\frac{C_{x x}(j)}{2}\left(\begin{array}{c}
\left.2 D_{\circ}-\frac{C_{x x}(j)}{2}\right) \\
x
\end{array}\right),\right. \\
\overline{H\left(x_{i}, x_{i+j}\right)}=\frac{1}{T} \sum_{j=1}^{T} \log _{2}\left[\frac{\pi e \sqrt{\pi}}{2} G_{x x}(j) \cdot \sqrt{8-\pi g_{x x}^{2}(j)}\right],
\end{gathered}
$$

$$
\overline{\mathrm{H}\left(\mathrm{x}_{\mathrm{i}}, \mathrm{x}_{\mathrm{i}+\mathrm{j}}\right)}=\frac{1}{\mathrm{~T}} \sum_{\mathrm{j}=1}^{\mathrm{T}} \log _{2}\left[\pi^{2} \mathrm{e} \frac{\mathrm{M}_{\mathrm{x}}-\mathrm{F}_{\mathrm{xx}}(\mathrm{j})}{\sigma_{\mathrm{x}}} \sqrt{\frac{8 \sigma_{\mathrm{o}}}{\pi}-\left[\mathrm{M}_{\mathrm{x}}-\mathrm{F}_{\mathrm{xx}}(\mathrm{j})\right]^{2}}\right],
$$$$
\text { де } \rho_{x x}(j)=1-\frac{\pi}{4} g_{x x}(j) \text {; }
$$

$$
R_{x x}(j)=D_{\grave{\circ}} \cdot \rho_{x x}(j) \text {; }
$$$$
g_{x x}(j)=\frac{G_{x x}(j)}{\sigma_{x}}-\text { нормована модульна функ- }
$$

ція автокореляції.

Реалізуючи обчислення оцінки $\overline{H\left(x_{i}, x_{i+j}\right)}$ на ковзному інтервалі, можна алгоритмічно просто здійснити ідентифікацію інформаційних станів технологічних об'єктів контролю та управління в реальному масштабі часу.

\section{5. МОДЕЛЬ ГЛОБАЛЬНОЇ ДИСПЕРСІї}

Ефективним засобом обробки сигналів та математичного моделювання складних динамічних об'єктів керування є модель глобальної дисперсії, яка дозволяє здійснити системну оцінку багатоканального ДІ, коли аналітичні співвідношення між даними в каналах не існують або складно знаходяться і мають громіздкий вигляд. Така модель побудована на основі матриці коефіцієнтів взаємокореляції між сигналами в каналах ДІ. Кореляційна матриця для $m$-канального джерела має розмірність $m \times m$ і симетрична відносно головної діагоналі, оскільки

$$
\begin{aligned}
& r_{i j}=\left\{\begin{array}{l}
r_{j i}, \text { при } i \neq j, \\
1, \text { при } i=j ;
\end{array}\right. \\
& \text { де } i=\overline{1, m}, \quad j=\overline{1, m} ., r_{i j}=r_{j i}
\end{aligned}
$$

Тому інформаційними є елементи матриці, розміщені під/над головною діагоналлю. Якщо цим елементам присвоїти порядкові номери, то отримаємо вибірку коефіцієнтів взаємокореляції об'ємом $N=\frac{m}{2} \cdot(m-1)$ (рис. 3$)$.

На основі відомого виразу знайдемо для даної вибірки глобальну дисперсію:

$$
D_{G}=\frac{1}{N} \sum_{s=1}^{N} r_{s}^{2} \text {. }
$$

Отримана таким шляхом оцінка дисперсії називається глобальною (рис. 3), завдяки тому, що характеризує загальний стан ДІ, з врахуванням статистичних взаємозв'язків між даними в різних каналах без аналізу даних в окремих каналах.

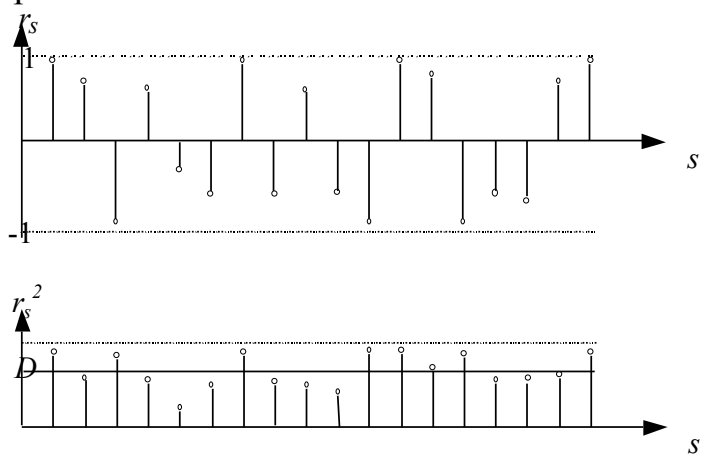

\section{Рис. 3. Решітчаста функція коефіцієнтів взасмокореляції та розраховане на їх основі значення глобальної дисперсії.}

Врахування різної семантичної значимості переходів між станами об'єкта управління при побудові глобальної дисперсії дозволяє більш 
повно охарактеризувати стан джерела інформації. Ефективність використання глобальної дисперсії значно зростає, особливо на об'єктах з великою різницею ваги переходів. Семантичну глобальну дисперсію можна описати функцією:

$$
D_{S}=\frac{1}{N} \sum_{s=1}^{N} p_{s} \cdot r_{S}^{2}
$$

де $0 \leq p_{s} \leq 1-$ вагова функція.

Введення вагової функції $p_{s}$ призводить до підвищення динаміки глобальної дисперсії, що свідчить про більшу чутливість моделі.

Визначаючи кореляційну матрицю для багатоканального ДІв дискретні моменти часу на інтервалі спостереження $T$, можна побудувати решітчасту функцію глобальної дисперсії $D_{G}$ або $D_{S}$ на цьому інтервалі (рис. 4).
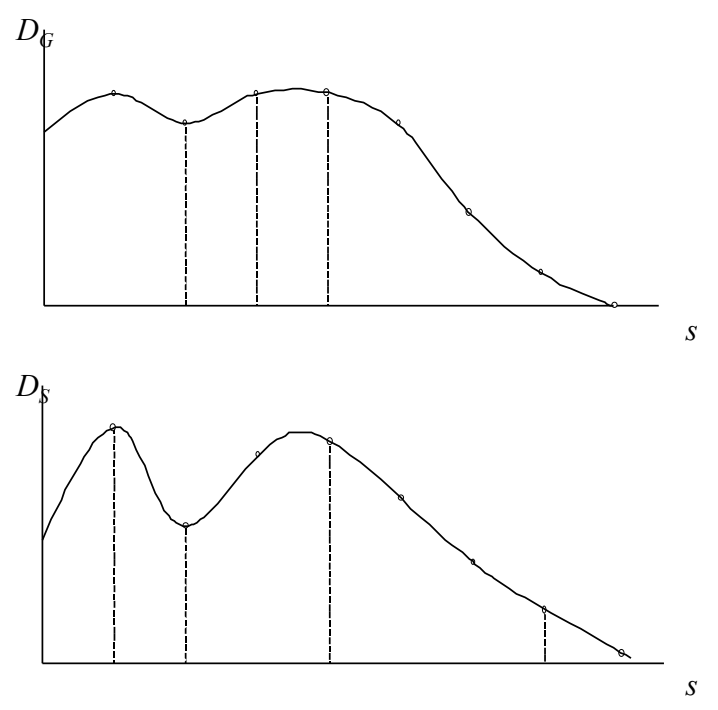

Рис. 4. Графік зміни глобальної дисперсії.

Значення оцінок $D_{G}$ і $D_{S}$, як видно з формул (11)-(12), відображають середньостатистичні значення кореляційних зв' язків між сигналами в каналах ДІ в квадратичному просторі. При зменшенні статистичної залежності між сигналами в каналах ДІ відповідно зменшуються коефіцієнти $r_{i j}$. Загальна тенденція зменшення коефіцієнтів $r_{i j}$ призводить до зменшення $D_{G}\left(D_{S}\right)$, що свідчить про руйнування взаємозв'язків в середині системи. В граничному випадку, коли $\forall i \neq j \quad r_{i j}=0$, то $D_{G}=0\left(D_{S}=0\right)$ і можна зробити висновок про руйнування всіх зв'язків і повний розвал системи.

Запропоновані методики побудови глобальної дисперсії $є$ важливим інструментом для системного контролю станів складних багатоканальних об' єктів управління і можуть знайти широке застосування в автоматизованих системах управління об'єктів нафтогазової, енергетичної, атомної та інших галузей промисловості.

\section{6. ЛОГІКО-СТАТ ИСТИЧНІ ІНФОРМАЦІЙНІ МОДЕЛІ (ЛСІМ).}

Для сигналізаціїта ідентифікації відхилень від норми дискретних джерел інформації в роботі [7] теоретично обгрунтовано набір логікостатистичних інформаційних моделей (ЛСІМ). До цього класу моделей на основі глобальної дисперсії додано ще одну модифікацію ЛСІМ 5. Вона дозволяє зафіксувати зменшення значень $D_{G}$ нижче встановленої апертури $E 5$, що відповідає руйнуванню кореляційних зв' язків і деградації системи в цілому. На відміну від ЛСІМ, які представлено в роботі [7], дана модель виражається однією булевою змінною $g$, яка оцінює загальний стан багатоканального ДІ:

$$
\begin{array}{r}
L 5=\left\{g_{1}, g_{2}, \ldots, g_{m}\right\}, \\
g=\left\{\begin{array}{l}
0, \text { при } D_{G}>E 5, \\
1, \text { при } D_{G} \leq E 5 .
\end{array}\right.
\end{array}
$$

ЛСІМ хоч і не дозволяють кількісно оцінити відхилення параметрів сигналів ДІ, проте здатні ефективно відслідковувати критичні відхилення від норми, що відповідають виходу значень параметрів за визначені апертури. Суттєвою перевагою ЛСІМ є також значне зменшення надлишковості повідомлень, що формуються на низових рівнях автоматизованих систем, за рахунок використання однобітної системи кодування.

Використання комплексу моделей дискретних джерел інформації дозволяє оперативно отримувати інформацію про динамічні об'єкти керування i, відповідно, здійснювати більш ефективний контроль та управління ними із застосуванням комп'ютерних систем реального часу.

\section{7. ВИСНОВКИ}

Актуальна на сьогоднішній день проблема моделювання можливих процесів в динамічних системах різної фізичної природи може бути в багатьох випадках успішно розв'язана за допомогою їхнього представлення як дискретних джерел інформації (ДДІ). 3 цієї метою 
необхідно комбінувати опис динамічних об'єктів на основі систем диференціальних рівнянь 3 їх представленням за допомогою статистичних, кореляційних, ентропійнихта логіко-статистичних моделей. Застосування апарату моделей ДДI дозволяє в реальному часі одержати інформацію про керовані об'єкти та, відповідно, реалізувати ïx найефективніший контроль 3 використанням комп'ютерних систем реального часу.

\section{ЛITЕРАТУРA}

1. Муль О.В. Дослідження впливу керованих параметрів машинного агрегату на характер автоколив альних прочесів у його виконавчих механізмах // Вісник ТДТУ імені I. Пулюя. - 1998. - T.3, № 3. - С. 163-170.

2. Николайчук Я. М., Сегін А. І. Моделі джерел інформації та методи їх представлення // Методи та прилади контролю якості. ІФДТУНГ, 1998, №2. С. - 80-84.

3. Низові обчислювальні мережі. Навч.

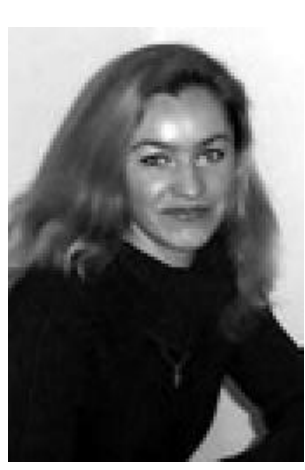

Олена Муль в 1994 p. закінчила Державний універcumem "Львівська політехніка" за спеиіальністю “Прикладна математика”. З 1994 р по 1998 р. навчалася в аспірантурі при Інституті кібернетики НАНУ (м. Київ) без відриву від виробництва. В 2000 р. захистила кандидатську дисертацію за спеціальністю 01.05.04 - "Системний аналіз та теорія оптимальних рішень”. 32001 р. доцент кафедри “Спеціалізованих комп'ютерних систем" Тернопільської академії народного господарства.

Коло наукових інтересів: аналіз складних динамічних систем з розподіленими та дискретними параметрами.

Андрій Сегін в 1997 р. закінчив Івано-Франківський державний технічний універcumem нафрти і газу, фракультет "Автоматизації і електрифрікації” за спеціальністю "Автоматизоване управління в технічних $i$ організаційних системах". З 1997 р по 2000 p. навчався в аспірантурі при Івано-Фран-

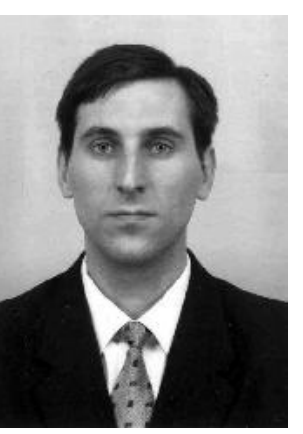
ківському державному технічному університеті нафрти і газу на стаціонарному відділенні. В 2001 р. захистив кандидатську дисертацію посібник. / Я. М. Николайчук. - К. : УМК ВО, 1990. $-55 \mathrm{c}$

4. Белима А. С., Боличевцеев О.Д., Гребень Й.І. Теоретичні основи ияентралізованого контролю технологічними процеесами. - К.: Вищза шк., 1973. - 242 с.

5. Сегін А. I. Подання інформаційних моделей та методика їх побудови // Розвідка $i$ розробка нафтових $i$ газових родовищ.. Івано-Франківськ: ІФДТУНГ, Серія: технічна кібернетика та електрифікація об'єктів паливно-енергетичного комплексу. - 1997. T.6, №34. - C. 23-34.

6. Лапа В. Г. Математические основы кибернетики. - К.: И-во “Выщ̧а школа”, 1974. - 452c.

7. Николайчук Я. Н. и др. Идентификация информационных состояний объектов исследования и управления на основе системы логико-статистических информационных моделей. К. Препринт 88-45 ИК АН УССР, 1988. - 16 c.

за спеціальністю 01.05.02. - “Математичне моделювання та обчислювальні методи". 32001 p. старший викладач кафедри "Спеціалізованих комп'ютерних систем” Тернопільської академії народного господарства.

Коло наукових інтересів: теорія та моделі джерел інформації, цифрова обробка сигналів, вертикальна інфоораційна технологія в базисі Галуа, теоретико-числові перетворення в системі залишкових класів та базисі Галуа. 